\title{
Sustainable prefabricated buildings: a holistic approach
}

\author{
Katerina Tsikaloudaki ${ }^{*}$, Theodore Theodosiou, Stella Tsoka, and Panagiotis Chastas \\ Civil Engineering Department, Aristotle University of Thessaloniki, Thessaloniki, Greece
}

Received: 30 June 2021 / Received in final form: 31 December 2021 / Accepted: 31 December 2021

\begin{abstract}
Although modern prefabricated buildings may offer many advantages, such as a significant reduction in cost and time, improved quality and accuracy in manufacture, easy dismantle and reuse of its components, etc., they have not gained the attention they deserve in the construction market yet. In this paper, a holistic approach for the formation of prefabricated buildings of advanced performance is presented. Within this context, a new, innovative prefabricated building element is developed, designed to exhibit optimized structural, hygrothermal, energy, acoustic, fire and environmental performance. The improved properties of the building element are ensured by the proper configuration of the layers that compose it with respect to the design objectives; for example, in order to support the heat storage and the control of indoor temperatures, the integration of PCMs in the element's layers is investigated. Furthermore, in order to indicate the contribution of the new building element to the sustainability of the overall construction, the performance of a building formulated with the new element is analyzed in terms of energy and environmental behaviour. The new building element and construction system are expected to systemize the prefabricated element's production, leading eventually to the improvement of the building quality, as well as to the reduction of time and cost of building's erection. In parallel, the new certified and optimized building performance will increase the share of prefabricated buildings in the Mediterranean countries, where housing needs are gradually growing, while at the same time, energy efficient and environmentally friendly construction will be promoted.
\end{abstract}

\section{Introduction}

Although the building stock across Europe is heterogeneous, across all member states the majority of the floor area is used for residential buildings. Their share varies considerably from about $60 \%$ in Central and Northern Europe to more than $80 \%$ in the southern countries. Similarly, the type of dwellings differs significantly across the EU; in the United Kingdom and Ireland, single-family dwellings are the dominant type (above 80\%), while in Greece, Spain and Italy, multi-family dwellings represent more than $70 \%$ of all dwellings. In the whole EU, there is almost an equal share between single- and multi-family buildings [1]. In Southern European countries, the dominant material for the buildings' envelope is the brick masonry. Prefabricated buildings, the basic forms of which are designated for single-family buildings and are made of wood, steel or concrete, account for only $15 \%$ in Europe but the rate is growing. Lower penetration of prefabricated buildings in the building industry is met in the Mediterranean countries [2]. For many years, prefabricated buildings

\footnotetext{
* e-mail: katgt@civil.auth.gr
}

were regarded as of inferior quality or designated for temporary constructions. But today, things have changed; prefabricated buildings compete the conventional ones in every aspect of performance, i.e., structural, thermal, acoustic, fire, environmental, etc.

In low rise, prefabricated buildings (i.e., up to $2-3$ storeys above ground) the most widespread material for the structural framework is steel, given that steel structures offer easy and fast on site installation, as well as the potential for design adaptability. However, in most prefabricated steel constructions, the wall elements are made of lightweight panels, which do not participate in the structural performance of the building. This leads to the increase of the total steel weight, and consequently the cost and the environmental impact of the building. Besides, the use of light weight building elements decreases the thermal mass of such building types, with negative impacts on the control of interior temperature and increased possibility of overheating, thermal discomfort and increase of cooling energy needs during the warm period.

A practical and technical means to increase the thermal mass of lightweight buildings is to add elements made of heavy materials on the building enclosure, such as walls made by precast reinforced concrete, which has adequate 
thermal capacity. Concerning the precast concrete walls, two main types are discerned: monolithic elements and sandwich panels, both employing concrete for their construction.

The monolithic concrete elements are made in the factory and they are joined together in situ either through especially designed connectors [3-5] or with cast-in-place concrete [6-8]. A drawback of this system is that it results to heavy and thick elements, which burden their handling and slow the installation process.

The sandwich panels comprise of two (or three) concrete wythes that embed a layer of thermal insulation. In currently available solutions, the concrete wythes are made of concrete reinforced with steel bars in a mesh, carbon or glass textiles or fibres made of steel, glass or polypropylene [9]. The connection between the concrete wythes is realized with concrete connectors, metallic connectors or fibre reinforced polymer connectors [9] crossing through the insulation layer. The thermal insulation material is usually in the form of plates.

Nowadays, steel frames infilled with prefabricated loadbearing walls are widely used in steel and composite structures. The relevant research and innovations are mainly focused on the development of the precast loadbearing walls and the assessment of their performance.

Within this framework, the research project SU.PR.I.M. (SUstainable PReconstructed Innovative Module) aims at the development of an innovative building module with advanced properties that will act as a vertical wall element in prefabricated residential buildings. This new building module will satisfy high requirements for its operation and performance. Specifically, it will be able to bear and deliver safely all the imposed building loads; display advanced energy performance; demonstrate excellent hygrothermal behavior; provide acoustic insulation protection and resistance against fire actions; minimize its environmental footprint during its life cycle.

The multifunctional, innovative building element was developed through different studies, starting with the structural one and was optimized through the hygrothermal, energy, acoustic and fire performance studies [10]. Its main form is now finalized; it concerns a composite panel, composed of two lightly reinforced concrete plates, $5 \mathrm{~cm}$ thick each, which are positioned on either side of vertical (and occasionally diagonal) metal hollow elements. The cavity between the metal hollow elements is filled with thermal insulation boards, and the whole wall element is insulated with ETICS. The type and the thickness of the thermal insulation materials may vary, in order to satisfy different needs, i.e., with regard to the climate, the requirements for acoustic insulation or fire performance, etc. The versatility of the new building element and its ability to be adapted to different contexts and requirements, are listed among its significant advantages.

In order to further enhance the performance of the building element, the addition of PCM in the interior concrete panel is investigated. $\mathrm{PCM}$ in the form of powder with melting temperatures at $24^{\circ} \mathrm{C}$ and $28^{\circ} \mathrm{C}$ are inserted in the concrete mixture, at a concentration of $10 \%$. PCMs are expected to support the heat storage within the building element and support the control of interior surface temperature leading to enhanced energy behaviour [11].
The individual studies at the element's level indicated its advanced performance. It is however necessary to assess the performance of the new building element when used at the building's level, throughout its whole life cycle, including not only the materials' contribution, but also the construction phase [12]. In this paper, the energy and the environmental performance of a small one-family building, constructed with the new SU.PR.I.M. module is analyzed for different alternatives of thermal insulation and for PCM application.

\section{Methodology}

The study concerns a small one-family building, presented in Figure 1. It has one storey and covers an area of $47.32 \mathrm{~m}^{2}$. The plan is rectangular, expanded along the south-north axis, with openings only on the south and north walls. The roof is inclined, covered with clay tiles and insulated with a layer of $10.0 \mathrm{~cm}$ of XPS. The floor of the house, in contact with the ground, is constructed with reinforced concrete and is insulated with a $10 \mathrm{~cm}$ thick XPS layer. The windows comprise of PVC frame with a double, low-e glazing, with an average value of $2 \mathrm{~W} /\left(\mathrm{m}^{2} \mathrm{~K}\right)$.

The walls of the building are constructed with the new SU.PR.I.M. building element, having two configurations: the standard one, as described in Section 1, and the enhanced with PCM alternative, for which PCM was added at $10 \%$ concentration on the concrete mixture forming the inner concrete panel. Both configurations are insulated with ETICS with four different thermal insulation thicknesses: $5 \mathrm{~cm}, 10 \mathrm{~cm}, 15 \mathrm{~cm}$ and $20 \mathrm{~cm}$ of XPS.

The energy performance of the building was assessed taking into account different climate conditions. It was assumed that the building was located in two different locations, one representative of the warmest climate zone of Greece (CMZ A: Heraklion, Lat. $35^{\circ} 19^{\prime} \mathrm{N}$; Long. $25^{\circ} 08^{\prime} \mathrm{E}$ ) and one for the coldest climate zone (CMZ D: Grevena, Lat. $40^{\circ} 05^{\prime} \mathrm{N}$; Long. $21^{\circ} 25^{\prime} \mathrm{E}$ ).

The energy analysis was performed with EnergyPlus, a dynamic simulation tool, commonly used for such purposes. In terms of the operational schedules of the house, involving occupancy, lighting, equipment, heating and cooling setpoints and infiltration rates, they have been set according to the respective values provided by the Technical Guides of the recast of the Hellenic Building Energy Performance Regulation. Furthermore, in order to simulate in a more realistic way the performance of the building during summer, it has been considered that the occupants will naturally ventilate the building during the cooling period, provided that the outdoor air temperature is lower than the indoor one by at least $1.0^{\circ} \mathrm{C}$. The simulations were conducted on an annual basis and the ideal load HVAC system has been employed in the model. The Domestic Hot Water (DHW) needs were also calculated, for the two climate contexts, according to the Hellenic Regulation for Building Energy Performance, EN 15316-3.2 and EN 15316-3.3.

The environmental assessment follows the energy performance analysis and examines the building for the four different scenarios of external thermal insulation 

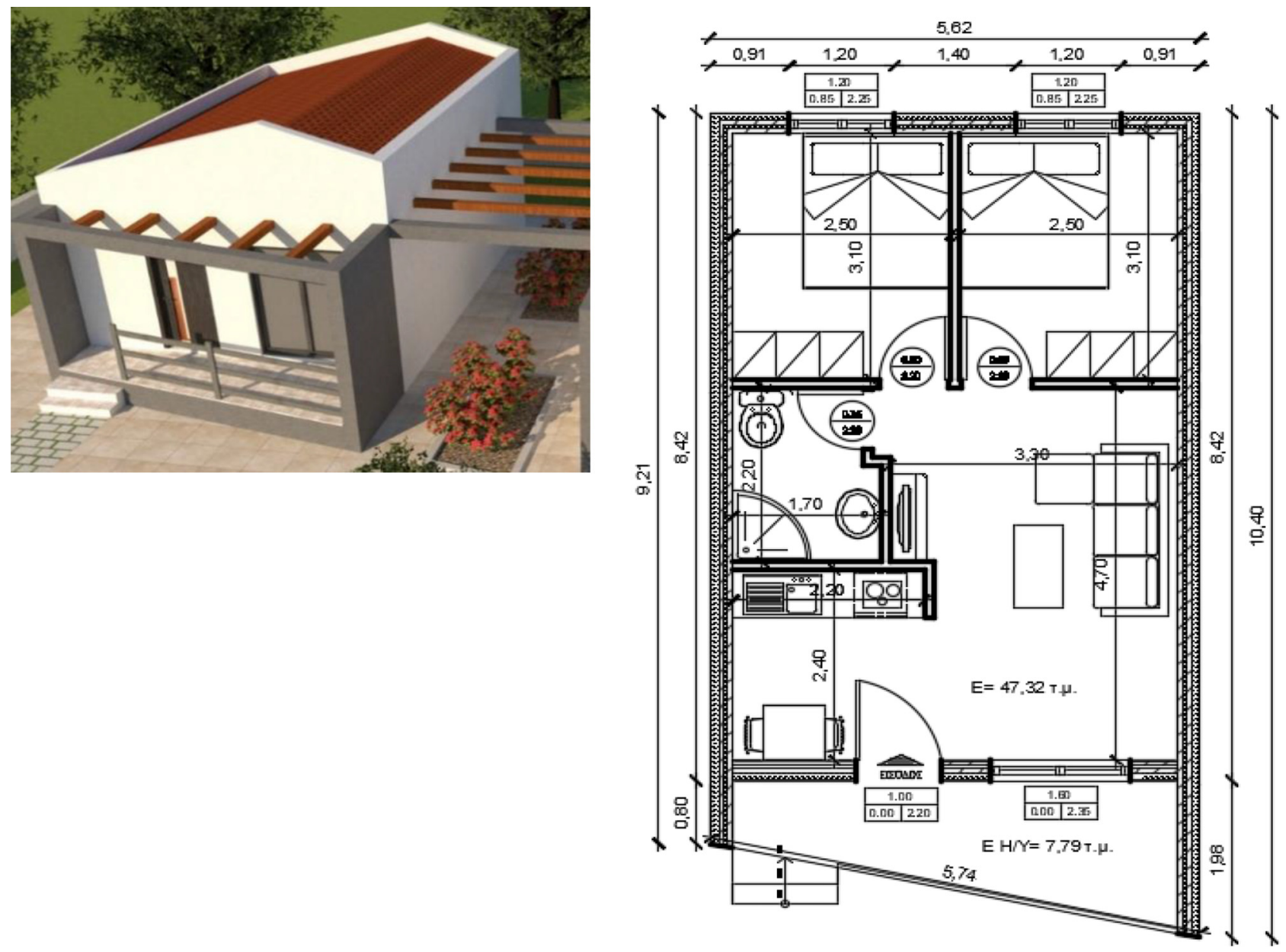

Fig. 1. External 3D view and plot of the examined house.

thicknesses (XPS: $5 \mathrm{~cm}, 10 \mathrm{~cm}, 15 \mathrm{~cm}$ and $20 \mathrm{~cm}$ ), the two climate contexts (zones A and D) and the possibility of PCM application in the concrete.

The environmental impact, within the system boundaries (Fig. 2), is calculated according to the principles of ISO 14040, ISO 14044, EN 15804 and EN 15978. Ecoinvent database provides the environmental (LCI) data, while all remaining information and inputs derive from the building construction plans, the Greek market and from personal communication with the prefabricated building manufacturer. The LCI data and the bill of quantities (Fig. 2) provide the environmental impact for the upstream and core processes of the building's life cycle. Additionally, the consideration of each material's and component's reference service life - as derived from international literature, ISO 15686-8 and EN 15459-leads to the calculation of the impact that relates to their replacement (B4, Fig. 2) during the building's life cycle.

The operating environmental impact (B6, Fig. 2) calculations are based on the results of the energy performance analysis (inputs) and the consideration of a gas boiler for heating and DHW and an air-to-air heat pump for cooling.

The end-of-life scenario relates to the demolition/ deconstruction (C1, Fig. 2) of the building (hydraulic digger) at the end of its life cycle and the transportation (C2, Fig. 2) of the waste to the nearest management facility (50 km distance). The present analysis does not consider any procedures for the waste management due to the lack of available or reliable data for Greece.

Finally, the environmental impact is calculated per square meter of reference/heated building area, for the 50-year building lifespan and for the impact indicators of methods CML-IA Baseline and Cumulative Energy Demand (CED); following the principles of Product Category Rule (PCR) 2014:02 for buildings within the context of the Environmental Product Declaration (EPD) system.

\section{Analysis of the building energy performance}

Figure 3 shows the energy needs for heating and cooling of the building with respect to the thermal insulation thickness and the use of PCM in the concrete mixture of the inner panel, when the building is located in the warm and the cold zone of Greece. It is observed that the energy needs are significantly lower for the building when located 


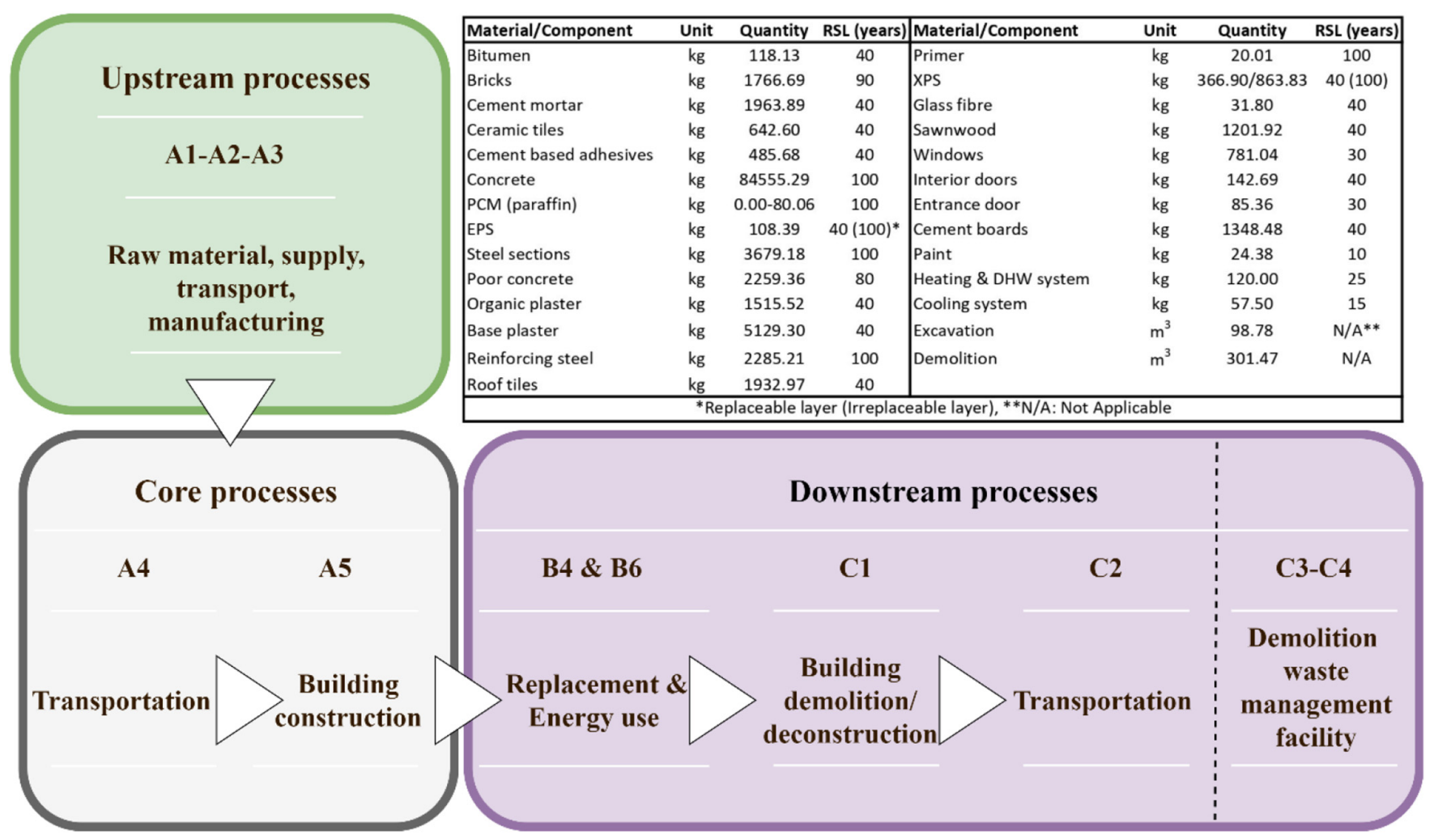

Fig. 2. System boundaries and life cycle processes for the analysed building. Bill of quantities.

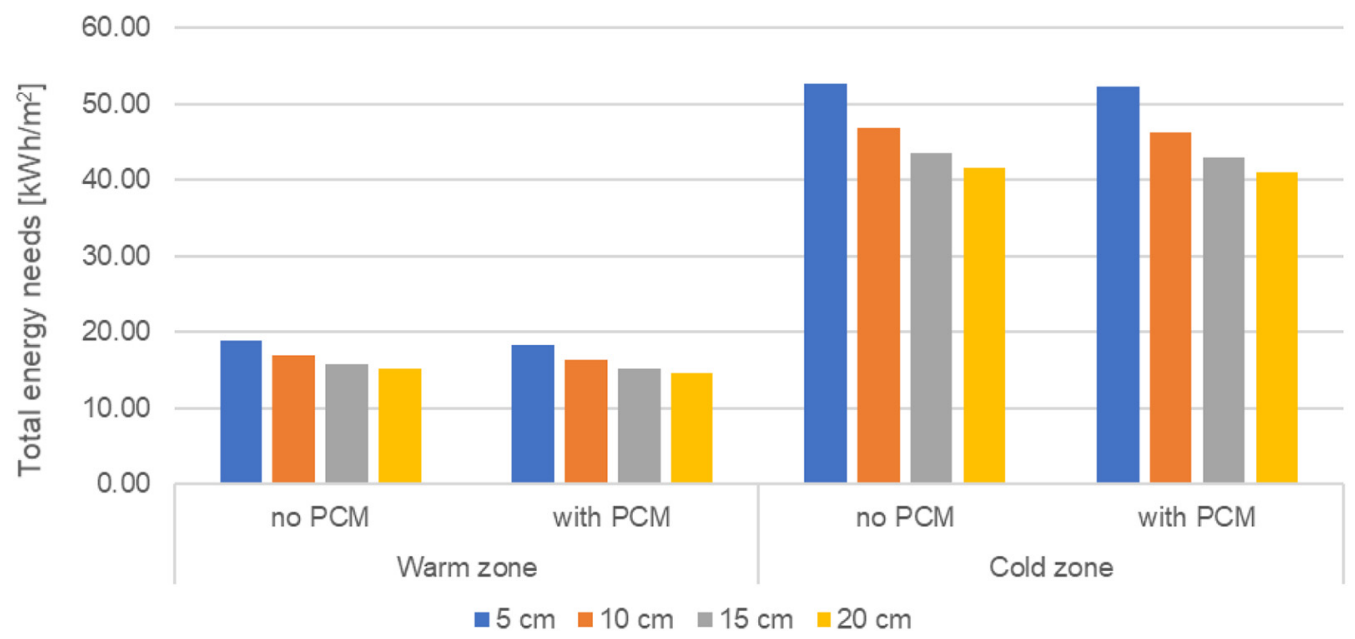

Fig. 3. The building energy needs for heating and cooling with respect to the thickness of thermal insulation and the use of PCM in the concrete of the inner panel, for the warm and cold climate zone.

in the warmest zone; in this location, more than $70 \%$ of this energy is used in order to cover the cooling needs and this percentage increases as the thermal insulation gets thicker. On the contrary, in the coldest zone, the heating needs are dominating; their share reaches $70 \%$ of the total energy needs and it decreases as the thermal protection gets stronger.

As expected, the total energy needs also decrease with the increase of thermal insulation. The decrease can reach $20 \%$ for both climate contexts, but it is not distributed evenly among the different thicknesses, as it is more substantial for lower insulation levels. It is worth mentioning that, when compared with conventional constructions, the building incorporating the SU.PR.I.M. element has advanced energy performance, as the energy demand can be by $15 \%$ lower for the same amount of thermal insulation [13].

The difference on total energy needs does not differentiate substantially when the PCMs are integrated in the inner concrete panel. The reduction is observed only in cooling loads and amounts up to 5\%. The monthly analysis of the derived results showed that that the PCMs perform better in June (when a reduction of up to $16 \%$ is 


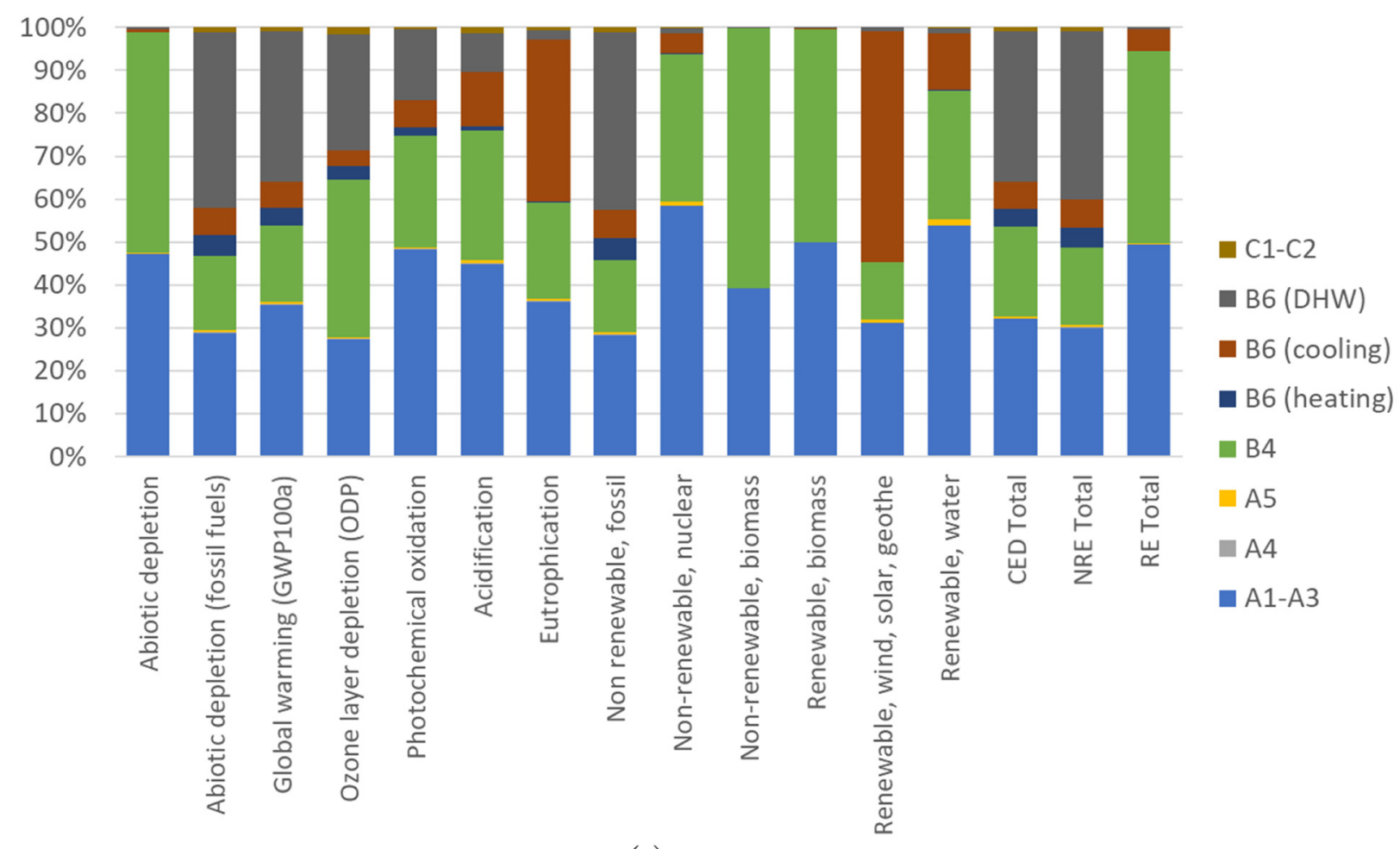

(a)
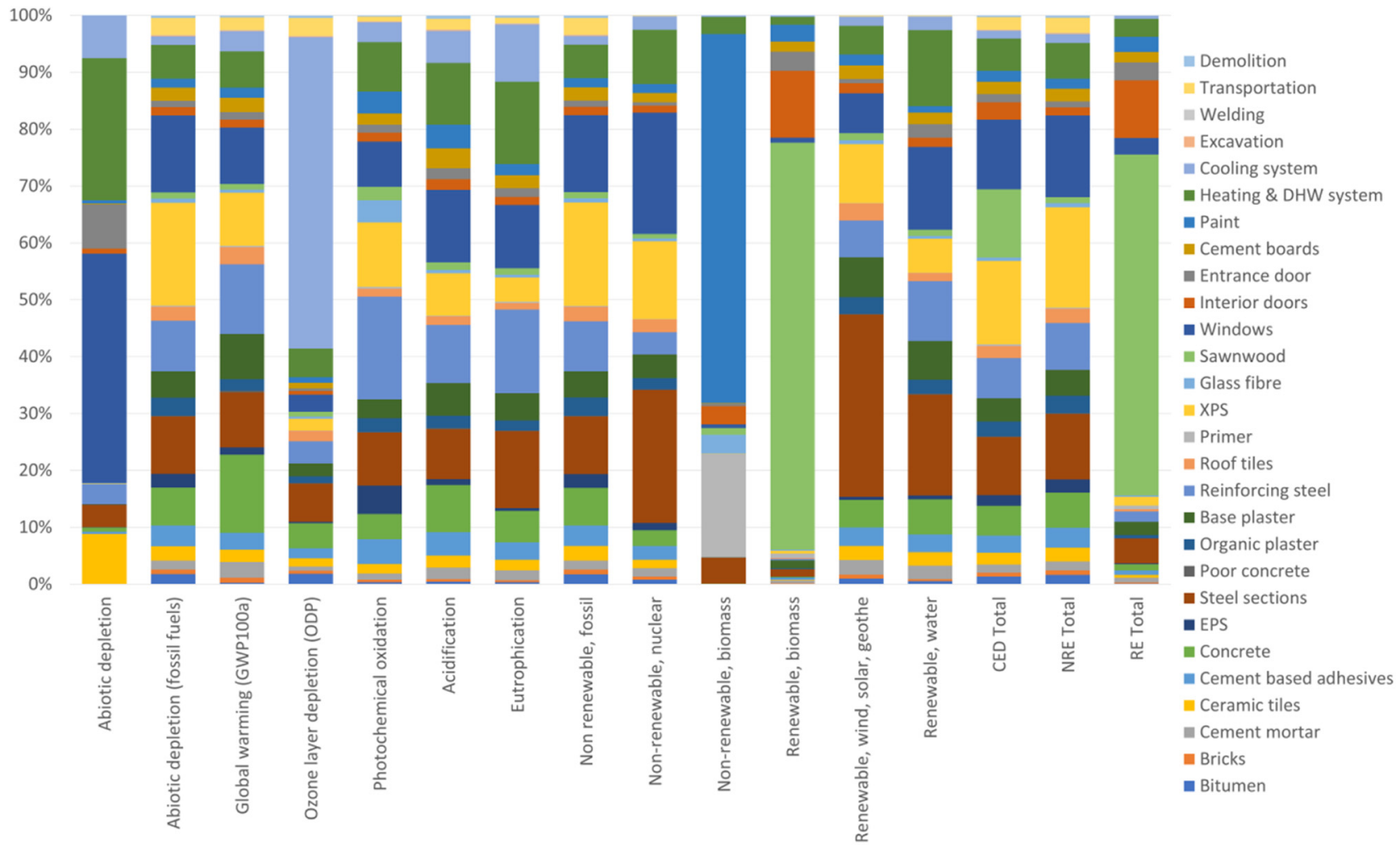

(b)

Fig. 4. Percentage contribution to the life cycle impact: (a) per life cycle process and (b) per material/component, within the system boundaries of the prefabricated building (base case scenario: no PCM, XPS $10 \mathrm{~cm}$ thickness and climate zone A of Greece). 


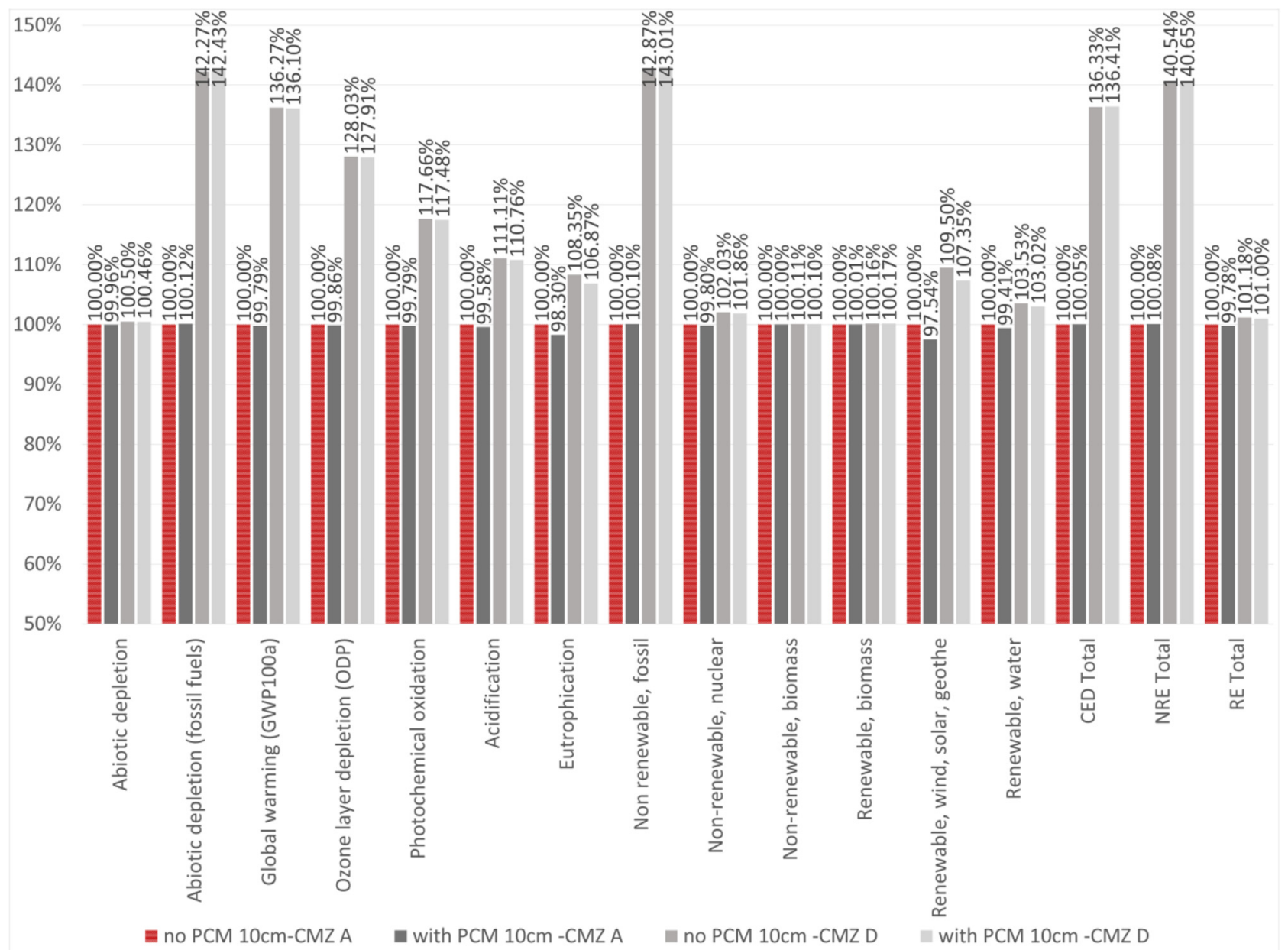

Fig. 5. Comparative analysis for the use of PCMs, per impact indicator, for the two CliMate Zones (CMZ: A and D) of Greece (the values are given in reference to the base case scenario: no PCM, $10 \mathrm{~cm}$ XPS thickness, zone A, red coloured hatch pattern).

observed with PCMs in the warm zone and up to $20 \%$ in the cold zone), while their performance falls in the following months. Additionally, it seems that the PCM can have a more significant impact on the formation of the cooling needs for lower insulation levels. This can be attributed to the heat discharge and recharge phases that are more intense when the thermal insulation is not increased.

\section{Analysis of the building environmental performance}

The results indicate average (including all indicators, Fig. 4a) contribution to the total life cycle impact for the upstream processes (A1-A3) of about $40.0 \%$, while for the core processes (A4-A5) this value tends to $0.55 \%$. The replacement of materials and components (B4) contributes with $30.7 \%$ to the total life cycle impact and the energy use-operating phase (B6) with a total of $28.2 \%$ (heating $1.9 \%$, cooling $10.6 \%$, DHW 15.7\%). Finally, the downstream end-of-life processes $(\mathrm{C} 1$ and $\mathrm{C} 2)$ relate only to $0.55 \%$ share to the life cycle impact of the building, which could be explained by the exclusion of the waste management processes ( $\mathrm{C} 3$ and $\mathrm{C} 4)$ from the system boundaries regarding the data availability. The percentage contribution changes for the coldest context (zone D), where those values differentiate mainly due to the increasing importance of the operating requirements and consequently of the consumptions, which lead to the percentage contribution for the energy use-operating phase (B6) of about 35.7\% (heating $10.55 \%$, cooling $10.8 \%$, DHW $14.35 \%$ ), for the scenario of $10 \mathrm{~cm}$ XPS thickness and zone D.

Considering only the embodied impact (Fig. 4b, base case scenario), the results highlight as the main average impact contributors: the windows $(12.04 \%)$, the steel sections (11.63\%), the heating and DHW system (8.81\%), the XPS insulation (7.78\%) and the cooling system (7.29\%). It must be noted that incorporating PCMs relates only to their average contribution of $0.18 \%$ to the total life cycle impact of the building.

Figure 5 shows the impact of the use of PCMs in the environmental performance indicators, when the building is located in the warmest (CMZ A) and the coldest (CMZ D) climate zones of Greece. More specifically, the graph shows the differentiation on each indicator's value with reference to the base case scenario, which concerns no 
PCM, $10 \mathrm{~cm}$ XPS thickness, zone A, and is displayed with the red coloured hatch pattern.

Through this comparative analysis it is shown that the potential application of PCMs does not cause any significant differentiations in the life cycle impact of the analysed building variations. In all impact indicators except for abiotic depletion (fossil fuels), non-renewable fossil fuels, renewable biomass, NRE Total and CED Total - incorporating PCMs into the inner concrete layer leads to an average decrease between $-0.45 \%$ and $-0.54 \%$ in the total life cycle impact. On the contrary, in those five categories, using PCMs slightly increases the total life cycle impact (between $+0.05 \%$ and $+0.08 \%$ ) due to their higher environmental load in those indicators that cannot be compensated by the reduction in the building's energy consumption. Hence, in this case, the decreased life cycle efficiency of PCMs mostly correlates with the reduced energy savings that in the present study relate only to the cooling loads; which according to the Hellenic Regulation for Building Energy Performance when they transform into consumptions they represent $50 \%$ of the actual values and consequently of the actual energy savings due to the use of PCMs.

\section{Conclusions}

In this paper, the performance of an innovative prefabricated wall system is assessed, when introduced in a small residential unit. More specifically, the wall system was designed in order to enhance the building's structural performance by carrying axial, lateral and dynamic forces, while at the same time, the thermal insulation that is embedded into the panel advances the energy efficiency and the sustainability of the building element, while the concrete layers provide the necessary thermal mass. In order to highlight the contribution of thermal mass on the performance of prefabricated buildings, the integration of PCMs on the new building element is additionally considered.

The present study focuses on the assessment of the energy and the environmental aspects of a single family building, under different climate contexts.

It is obvious that the integration of the new building element to the building's envelope contributes to low energy needs for heating and cooling, especially when a warm climate is concerned. The addition of PCMs into the concrete mixture leads to the reduction of the cooling load, but only at a limited extent. It has to be mentioned, that even without the PCMs, the energy performance of a building constructed with the new element is significantly improved.

Life cycle assessment reflects the climate dependency of results and indicates an increase of about $+7.5 \%$ in the average contribution of the operating to the total life cycle impact of the building between zones A (warm) and D (cold) of Greece. On average, the upstream, the operating and the replacement processes contribute with about $1 / 3$ each to the total life cycle impact of the building. Finally, PCMs' average contribution limits to $0.18 \%$, while their application slightly differentiates the results with a minor reduction in the total life cycle impact for the majority of the indicators.

The analysis showed that the addition of PCM may show better energy results, but when it comes to the overall environmental performance their contribution is negligible. What is more important is the conclusion that through careful design the performance of prefabricated buildings can reach high levels -even higher than the one of conventional buildings- in contrast to what was widely believed some years ago.

\section{Conflict of Interest}

The authors declare that they have no conflict of interest.

\section{Funding}

This research has been co-financed by the European Regional Development Fund of the European Union and Greek national funds through the Operational Program Competitiveness, Entrepreneurship and Innovation, under the call RESEARCH - CREATE - INNOVATE (project code:T1EDK-03042).

\section{Authors contributions}

K.T., T.T., S.T. and P.T. conceived and designed the study. S.T. and T.T. performed the numerical simulations for the energy performance and C.P. performed the assessment for the environmental performance. K.T. and C.P. wrote the paper, S.T. and T.T. reviewed and edited the manuscript. K.T. is responsible for the project's supervision, coordination and funding.

Acknowledgment. This research has been co-financed by the European Regional Development Fund of the European Union and Greek national funds through the Operational Program Competitiveness, Entrepreneurship and Innovation, under the call RESEARCH - CREATE - INNOVATE (project code: T1EDK-03042).

\section{References}

1. EU Building Stock Observatory. https://ec.europa.eu/ener gy/eu-buildings-database_en, accessed 27/04/ 2020

2. F. Apaydin, Effectiveness of prefabricated house industry's marketing activities and Turkish consumers' buying intentions towards prefabricated house, Asian Soc. Sci. 7, 267-276 (2011)

3. H. Hou, X. Yan, B. Qu, Z. Du, Y. Lu, Cyclic tests of steel tee energy absorbers for precast exterior wall panels in steel building frames, Eng. Struct. 242, 112561 (2021)

4. D. Dan, C. Todut, V. Stoian, M. Fofiu, Theoretical and experimental study of precast reinforced concrete walls with different openings under seismic loads, Eng. Struct. 240, 112397 (2021) 
5. R. Vaghei, F. Hejazi, A. Akbar Firoozi, Analytical model for precast wall equipped with U-shaped steel channel connection, Structures 32, 406-432 (2021)

6. H. Hou, H. Ye, B. Qu, T. Ma, X. Liu, L. Chen, S. Zhang, Precast segmental reinforced concrete walls under eccentric compressive loading: an experimental study, Eng. Struct. 113, 79-88 (2016)

7. S. Singhal, A. Chourasia, Y. Kajale, D. Singh, Behaviour of precast reinforced concrete structural wall systems subjected to in-plane lateral loading, Eng. Struct. 241, 112474 (2021)

8. Q. Jiang, J. Shen, X. Chong, M. Chen, H. Wang, Y. Feng, J. Huang, Experimental and numerical studies on the seismic performance of superimposed reinforced concrete shear walls with insulation, Eng. Struct. 240, 112372 (2021)

9. R. O'Hegarty, O. Kinnane, Review of precast concrete sandwich panels and their innovations, Constr. Build. Mater. 233, 117145 (2020)
10. K. Tsikaloudaki, T. Theodosiou, C. Giarma, K. Kontoleon, D. Aravantinos, S. Tsoka, D. Tsirigoti, A. Karaoulis, P. Chastas, Building a new sustainable preconstructed building element, IOP Conf. Ser. 410 (2020)

11. Q. Al-Yasiri, M. Szabó, Paraffin as a phase change material to improve building performance: an overview of applications and thermal conductivity enhancement techniques, Renew. Energy Environ. Sustain. 6, Article Number 38 (2021)

12. J. Challender, Achieving sustainability and environmental enhancements through a "collaboration toolkit" to deliver new sustainability strategies for The Emirate of Ajman UAE, Renew. Energy Environ. Sustain. 6 (2021)

13. K. Tsikaloudaki, T. Theodosiou, S. Tsoka, P. Chastas, Conventional vs prefabricated buildings: pursuing the goal of sustainability, in International Conference Places and Technology, PT2020, Belgrade, autumn 2020

Cite this article as: Katerina Tsikaloudaki, Theodore Theodosiou, Stella Tsoka, Panagiotis Chastas, Sustainable prefabricated buildings: a holistic approach, Renew. Energy Environ. Sustain. 7, 11 (2022) 